\title{
ANALISIS PENENTUAN BIAYA PRODUKSI DENGAN MENGGUNAKAN METODE FULL COSTING UNTUK MENENTUKAN HARGA JUAL PADA PT. BLUE OCEAN GRACE INTERNATIONAL
}

\author{
Jonathan Julio Budiman¹, Ventje Ilat ${ }^{2}$, Lidia M. Mawikere ${ }^{3}$ \\ 1,2,3 Jurusan Akuntansi, Fakultas Ekonomi dan Bisnis Universitas Sam Ratulangi, J1. Kampus Bahu, Manado, \\ 95115, Indonesia
}

E-mail : jonathanjub@yahoo.com

\begin{abstract}
Company that focusing on creating profits, will definitely makes every effort to maintain the survival of its company. One of the ways to make more profit is to increase the selling price of its product. In carrying out the production process in order to produce a product that has a sale value,manufactures company will issue a variety of costs. These costs are classified into production emelents such as raw material cost,direct labor cost, and overhead factory cost. The purpose of this study is to apply the full costing method in order to set the selling price at the production cost. The analytical method that used in this study is qualitative with descriptive approach. The result of the study shows that the company in the way of setting the selling price indeed already calculating its production cost, but in calculating the factory overhead cost the company doesn't include the machine and equipment depreciation costs, component material cost, and insurance cost.
\end{abstract}

Keywords : production cost, full costing, selling price.

\section{PENDAHULUAN}

Untuk mempertahankan kelangsungan hidup perusahaan, perusahaan baiknya berfokuskan pada menciptakan laba. Perusahaan dapat menaikan harga jual produknya agar dapat menghasilkan laba, dan cara ini memang dapat mengasilkan laba yang lebih, namun cara ini sering kali akan membuat konsumen lari ke produk pesaing lain yang harga produknya tergolong lebih murah. Perusahaan akan mengeluarkan biaya-biaya dalam melakukan proses produksinya, Biaya-biaya ini dikenal dengan biaya produksi, yang mencangkup biaya bahan baku, biaya tenaga kerja langsung, dan biaya overhead pabrik. Bahan baku adalah bahan dasar yang digunakan utuk diolah oleh perusahaan. Tenaga kerja langsung ialah karyawan perusahaan yang berhubungan langsung dengan proses produksi. Overhead pabrik unsur biaya yang bukan merupakan biaya bahan baku dan biaya tenaga kerja.

Tiap perusahaan memiliki cara yang berbeda-beda dalam menentukan harga jual produknya, salah satunya perusahaan harus mengetahui jumlah biaya produksinya. Saat sebelum melakukan proses produksi, perusahaan harus mengetahui unsur-unsur dan faktorfaktor biaya apa yang akan dikeluarkan oleh perusahaan seperti membeli bahan baku. Pembelian bahan baku ini merupakan salah satu fungsi dari manajemen persediaan. PT. Blue Ocean Grace International adalah perusahaan manufaktur yang bergerak di bidang perikanan, yang terletak di kota Bitung. Perusahaan ini bergerak dalam pembuatan ikan tuna. Melihat sektor perikanan yang terus berkembang di Indonesia membuat perusahaan-perusahaan tertarik untuk membuka usaha bisnis khususnya di sektor perikanan.

\section{TINJAUAN PUSTAKA}

Akuntansi. Menurut ASOBAT (A Statement of Basic Accounting Theory) yang diterbitkan oleh $A A A$ pada tahun 1996, akuntansi didefinisikan sebagai proses 
mengidentifikasi, mengukur, dan menyampaikan informasi ekonomi bagi para pengguna dalam mempertimbangkan alternatif yang ada dan membuat kesimpulan (Hery, 2017 :1).

Akuntansi Manajemen. Akuntansi manajemen merupakan cabang dari ilmu akuntansi yang menghasilkan informasi akuntansi untuk keperluan pihak manajemen untuk pengambil keputusan.

Akuntansi Biaya. Akuntansi biaya adalah cabang dari ilmu akuntansi, yang menghasilkan informasi biaya-biaya yang berkaitan dengan kegiatan produksi perusahaan.

Biaya Produksi. Biaya produksi adalah biaya-biaya langsung, yang berhungan dengan proses produksi produk yang dihasilkan oleh perusahaan.

\section{Elemen Biaya Produksi}

1. Biaya Bahan Baku. Biaya bahan baku contohnya adalah ikan tuna sebagai bahan baku.

2. Biaya Tenaga Kerja Langsung. Contoh dari biaya tenaga kerja langsung adalah biaya gaji dari karyawan perusahaan.

3. Biaya Overhead Pabrik. Contoh dari biaya overhead pabrik adalah biaya pemeliharaan mesin, gedung, dan peralatan.

\section{Metode Pengumpulan Biaya Produksi}

1. Proccess Costing (Metode Biaya Proses), metode ini dihitung dengan cara menjumlahkan total biaya produksi, lalu dibagi dengan total produk dalam satuan. Perusahaan yang berproduksi secara massa menggunakan metode harga pokok proses.

2. Job order costing method (Metode Biaya Pesanan), metode ini dihitung dengan cara menjumlahkan total biaya produksi untuk pesanan, dan dibagi dengan total produk dalam pesanan tersebut. Perushaan yang yang produknya dipesan terlebih dahulu menggunakan metode harga pokok pesanan.

\section{Metode Penentuan Biaya Produksi}

1. Metode full costing. Metode full costing, yaitu metode yang menghitung atau membebankan seluruh biaya-biaya yang dikeluarkan dalam proses produksi.

2. Metode variable costing. Metode variable costing, adalah metode yang menghitung atau membebankan hanya biaya-biaya variable dalam proses produksi.

Full Costing. Metode full costing dikenal juga dengan metode harga pokok produk konvensional. Menggunakan metode full costing ini, jika saat produk belum terlaku dijual, dapat menunda pembebanan biaya-biaya overhead, dengan diahlikan untuk mengurangi atau menambah harga pokok dalam persediaan.

Harga Jual. Harga jual merupakan harga yang ditetapkan perusahaan dari total biaya produksi, dan ditambah dengan biaya non produksi serta laba yang diharapkan. Harga jual yang terlalu tinggi, akan menyebabkan konsumen membeli produk pesaing lainnya.

\section{METODE PENELITIAN}

Jenis Penelitian. Jenis penelitian yang digunakan dalam penelitian ini adalah penelitian kualitatif deskriptif.

Tempat dan Waktu Penelitian. Penelitian ini dilaksanakan di PT. Blue Ocean Grace International yang berlokasi di kompleks pelabuhan, perikanan samudera, Aertembaga, kota Bitung. Penelitian ini dilaksanakan pada bulan Juli 2018 hingga selesai.

Prosedur Penelitian. Langkah-langkah dalam melaksanakan penelitian di PT. Blue Ocean Grace International adalah sebagai berikut: 


\begin{tabular}{|c|}
\hline Tahap 1 \\
Mengajukan permohonan untuk mengadakan penelitian \\
\hline Tahap 2 \\
\hline $\begin{array}{c}\text { Mengumpulan data mengenai biaya produksi dengan } \\
\text { Wawancara dan Dokumentasi dengan PT. Blue Ocean Grace } \\
\text { International. }\end{array}$ \\
\hline Tahap 3 \\
Pengolahan Data \\
Tahap 4 \\
\hline Tahalan dan Pemberian Saran \\
\hline
\end{tabular}

\section{Sumber: Data Olahan}

\section{Gambar 1. Diagram Prosedur Penelitian}

1. Pada tahap 1 penulis mengajukan permohonan kepada direktur perusahaan untuk mengadakan penelitian di PT. Blue Ocean Grace International dengan surat permohonan penelitian dari Fakultas Ekonomi dan Bisnis.

2. Pada tahap 2 setelah penulis mendapat persetujuan dari perushaan dengan diberikannya surat balasan dari PT. Blue Ocean Grace International kemudian penulis akan melakukan pengumpulan data dengan cara wawancara dan dokumentasi dengan direktur dan karyawan dalam bidang produksi dan penjualan di perusahaan.

3. Pada tahap 3 setelah penulis mendapatkan data-data dari perusahaan yaitu biaya produksi perusahaan maka penulis melakukan pengolahan data.

4. Pada tahap 4 setelah penulis menyelesaikan pengumpulan data dan pengolahan data kemudian akan ditarik kesimpulan mengenai hasil dan pembahasan yang dilakukan oleh penulis. Selanjutanya penulis akan memberikan saran yang sesuai dengan hasil penelitian yang bisa bermanfaat bagi perusahaan.

\section{Jenis dan Sumber Data}

Jenis Data. Jenis data yang digunakan dalam penelitian ini adalah : (1) Data kualitatif, merupakan data yang disajikan dalam bentuk uraian; dan (2) Data kuantitatif, merupakan data yang disajikan dalam bentuk angka-angka.

Sumber Data. Sumber data yang digunakan dalam penelitian ini adalah data primer. Data primer adalah data atau informasi diperoleh melalui pertanyaan tertulis dengan menggunakan kuesioner atau lisan dengan menggunakan metode wawancara. Data yang didapat langsung oleh penulis dari objek penelitian melalui wawancara dan penelitian langsung ke perusahaan. Wawancara dengan pemilik usaha tentang asumsi dasar atau pedoman biaya-biaya yang dikeluarkan perusahaan untuk proses produksi.

Metode Pengumpulan Data. Metode pengumpulan data yang digunakan dalam penulisan ini adalah dengan penelitian lapangan (field research). Penelitian lapangan dilakukan dengan cara :

a. Wawancara. Penulis melakukan wawancara dengan pimpinan perusahaan dan karyawan perusahaan dalam bagian produksi dan penjualan. Pertanyaan-pertanyaan yang diajukan dalam wawancara adalah:

1. Bagaimana gambaran umum, sejarah, dan struktur perusahaan PT. Blue Ocean Grace International? 
2. Biaya-biaya apa saja yang dibebankan dalam biaya produksi perusahaan?

3. Bagaimana perusahaan menentukan harga jual produk?

b. Dokumentasi. Penulis mengumpulkan data dengan menggunakan arsip dan dokumendokumen berupa data biaya produksi perusahaan pada tahun 2015-2017

Metode dan Proses Analisis. Metode analisis yang digunakan adalah metode analisi deskriptif, dimana metode ini membahasa suatau permasalahan secara terperinci yang diawali dengan langkah mengumpulkan dan menyaring data yang diperoleh dari perusahaan, kemudian menguraikan dan menggambarkan suatau keadaan secara sistematis, factual dan akurat mengenai fakta-fakta, tarik suatu kesimpulan untuk menjawab permasalahn yang ada pada perusahaan, yaitu menganalisis penerapan full costing sebagai penentuan biaya produksi pada PT. Blue Ocean Grace International dan sebagai solusi untuk masalah yang diteliti oleh penulis. Teknik analisis yang digunakan dalam penelitian ini adalah sebagai berikut :

1. Menentukan biaya produksi dari produk tuna, diantaranya: (a) Biaya Bahan Baku; (b) Biaya Tenaga Kerja Langsung; dan (c) Biaya overhead pabrik.

2. Menentukan harga jual produk tuna loin.

\section{HASIL PENELITIAN DAN PEMBAHASAN}

\subsection{Hasil Penelitian}

Perhitungan biaya produksi PT. Blue Ocean Grace International mencangkup biaya bahan baku, biaya tenaga kerja, dan biaya overhead pabrik perusahaan: Dalam satu bulan produksi perusahaan memerlukan bahan baku sebanyak $19.500 \mathrm{~kg}$ dengan Frozen Yellowfin Tuna Loin Grade AAA (3 lbs up) sebesar 70\% dan Frozen Yellowfin Tuna Loin Grade A (1-3 $l b s)$ sebesar $30 \%$. Hasil akhir produk yang didapat setelah mengalami proses produksi adalah $70 \%$ dari bahan baku. Jadi perhitungan biaya produksi untuk produk Frozen Yellowfin Tuna Loin Grade AAA (3 lbs up) dan Frozen Yellowfin Tuna Loin Grade A (1-3 lbs) adalah:

Tabel 1. Perhitungan biaya produksi produk frozen yellowfin tuna loin grade AAA (3 lbs up) Jenis Biaya Jumlah Biaya (Rp.) Unit yang Di- Biaya per Unit (Rp) produksi (Kg)

\begin{tabular}{lrrr}
\hline Biaya Bahan Baku & Rp. 819.000 .000 & 9.555 & Rp. 85.714 \\
Biaya Tenaga kerja & Rp. 83.790 .000 & 9.555 & Rp. 8.769 \\
Biaya overhead pabrik & Rp. 110.008 .833 & 9.555 & Rp. 11.513 \\
Total & Rp. $\mathbf{1 . 0 1 2 . 7 9 8 . 8 3 3}$ & 9.555 & Rp. 105.996 \\
\hline
\end{tabular}

Sumber: PT. Blue Ocean Grace International

Tabel 1 menunjukan biaya bahan baku sebesar Rp. 819.000 .000 dibahagi dengan $9.555 \mathrm{~kg}$ tuna loin $=$ Rp. 85.714/kg untuk bahan baku. Biaya tenaga kerja sebesar Rp. 83.790.000 dibahagi dengan $9.555 \mathrm{~kg}$ unit tuna loin maka akan mendapatkan hasil Rp. 8.769. Dan biaya overhead pabrik sebesar Rp. 110.008 .833 dibahagi dengan $9.555 \mathrm{~kg}$ unit tuna loin akan mendapat hasil Rp. 11.513. Jadi total biaya produksi produk adalah Rp. 1.012.798.833.

Tabel 2. Perhitungan biaya produksi produk frozen yellowfin tuna loin grade A (1-3 lbs)

\begin{tabular}{lrrr}
\hline \multicolumn{1}{c}{ Jenis Biaya } & Jumlah Biaya (Rp.) & $\begin{array}{c}\text { Unit yang Di- } \\
\text { produksi (Kg) }\end{array}$ & Biaya per Unit (Rp) \\
\hline Biaya Bahan Baku & Rp. 351.000 .000 & 4.095 & Rp. 85.714 \\
Biaya Tenaga kerja & Rp. 35.910 .000 & 4.095 & Rp. 8.769 \\
Biaya overhead pabrik & Rp. 41.952 .500 & 4.095 & Rp. 10.244 \\
Total & Rp. 428.862.500 & 4.095 & Rp. 104.728 \\
\hline
\end{tabular}

Sumber: PT. Blue Ocean Grace International 
Tabel 2 menunjukan biaya bahan baku sebesar Rp. 351.000 .000 dibahagi dengan $4.095 \mathrm{~kg}$ tuna loin $=$ Rp. 85.714/kg untuk bahan baku. Biaya tenaga kerja sebesar Rp. Rp. 35.910.000 dibahagi dengan $4.095 \mathrm{~kg}$ unit tuna loin maka akan mendapatkan hasil Rp. 8.769. Dan biaya overhead pabrik sebesar Rp. 41.952 .500 dibahagi dengan $4.095 \mathrm{~kg}$ unit tuna loin akan mendapat hasil Rp. 10.244. Jadi total biaya produksi produk adalah Rp. 428.862.500. Dalam penentuan harga jual perusahaan memiliki beberapa produk diantaranya produk tuna loin yaitu Frozen Yellowfin Tuna Loin Grade AAA (3 lbs up) dan Frozen Yellowfin Tuna Loin Grade A (1-3 lbs). Harga jual produk tuna loin perusahaan menentukannya melalui biaya produksi, sehingga menambahkan mark up biaya. Untuk produksi Frozen Yellowfin Tuna Loin Grade AAA (3 lbs up), dengan bahan baku $13.650 \mathrm{~kg}$ perusahaan akan mendapatkan hasil unit sebesar $9.555 \mathrm{~kg}$. Perusahaan mempertimbangkan kualitas mutu ikan yang sangat baik pada produk Tuna Loin Grade AAA (3 lbs up dan perusahaan biasanya mengekspor produk ini ke luar negeri sehingga perusahan menetapkan harga jual produk dengan harga Rp. 120.000. Untuk produksi Frozen Yellowfin Tuna Loin Grade A (1-3 lbs), dengan bahan baku $5850 \mathrm{~kg}$ perusahaan akan mendapatkan hasil unit sebesar $4.095 \mathrm{~kg}$. Dengan kualitas mutu produk yang baik dan perusahaan menjual produk hingga ke luar kota maka perusahaan menetapkan harga jual produk sebesar Rp.110.000.

\subsection{Pembahasan \\ Penerapan Metode Full Costing}

Tabel 3. Perhitungan biaya produksi produk frozen yellowfin tuna loin grade AAA (3 lbs up)

\begin{tabular}{lrrr}
\hline \multicolumn{1}{c}{ Jenis Biaya } & \multicolumn{1}{c}{ Jumlah Biaya } & Unit yang Di-produksi (Kg) & Biaya per Unit \\
\hline Biaya Bahan Baku & Rp. 819.000 .000 & 9.555 & Rp. 85.714 \\
Biaya Tenaga kerja langsung & Rp. 83.790 .000 & 9.555 & Rp. 8.769 \\
Biaya overhead pabrik & Rp. 176.892 .800 & 9555 & Rp. 18.513 \\
Total & $\mathbf{1 . 0 7 9 . 6 8 2 . 8 0 0}$ & 9555 & Rp. 112.996 \\
\hline
\end{tabular}

Sumber: Data Hasil Olahan

Tabel 3 menunjukan bahwa total Perhitungan Biaya Produksi Produk Frozen Yellowfin Tuna Loin Grade AAA (3 lbs up) adalah Rp. 1.079.682.800.

Tabel 4. Perhitungan biaya produksi produk frozen yellowfin tuna loin grade A (1-3 lbs)

\begin{tabular}{lrrr}
\hline \multicolumn{1}{c}{ Jenis Biaya } & Jumlah Biaya & Unit yang Di-produksi (Kg) & Biaya per Unit \\
\hline Biaya Bahan Baku & Rp. 351.000 .000 & 4.095 & Rp. 85.714 \\
Biaya Tenaga kerja langsung & Rp. 35.910 .000 & 4.095 & Rp. 8.769 \\
Biaya overhead pabrik & Rp. 61.450 .394 & 4.095 & Rp. 15.006 \\
Total & Rp. 448.360.394 & 4.095 & Rp. 109.489 \\
\hline
\end{tabular}

Sumber: Data Hasil Olahan

Tabel 4 menunjukan bahwa total Perhitungan Biaya Produksi Produk Frozen Yellowfin Tuna Loin Grade A (3 lbs up) adalah Rp. 448.360.394. 


\section{Perbandingan Perhitungan Harga Jual}

Tabel 5. Perbandingan harga jual produk frozen yellowfin tuna loin grade AAA (3 lbs up)

\begin{tabular}{|c|c|c|}
\hline Jenis Biaya & Metode Perusahaan & Metode Full Costing \\
\hline Biaya Bahan Baku & Rp. 819.000 .000 & Rp. 819.000 .000 \\
\hline Biaya Tenaga kerja langsung & Rp. 83.790 .000 & Rp. 83.790 .000 \\
\hline Biaya overhead pabrik & Rp. 110.008 .833 & Rp. 176.892 .800 \\
\hline Biaya Produksi & Rp. 1.012.798.833 & Rp. 1.079.682.800 \\
\hline Laba yang diharapkan perusahaan (10\%) & & Rp. 107.968 .280 \\
\hline Total & Rp. 1.012.798.833 & Rp. 187.651.080 \\
\hline Unit yang dihasilakan & 9.555 & 9.555 \\
\hline Harga jual per Kg & Rp. 120.000 & Rp. 124.296 \\
\hline
\end{tabular}

Sumber: Data Hasil Olahan

Tabel 6. Perbandingan harga jual produk frozen yellowfin tuna loin grade A (1-3 lbs)

\begin{tabular}{lrr}
\hline \multicolumn{1}{c}{ Jenis Biaya } & Metode Perusahaan & Metode Full Costing \\
\hline Biaya Bahan Baku & Rp. 351.000 .000 & Rp. 351.000 .000 \\
Biaya Tenaga kerja langsung & Rp. 35.910 .000 & Rp. 35.910 .000 \\
Biaya overhead pabrik & Rp. 41.952 .500 & Rp. 61.450 .394 \\
Biaya Produksi & Rp. $\mathbf{4 2 8 . 8 6 2 . 5 0 0}$ & Rp. 448.360.394 \\
Laba yang diharapkan perusahaan (10\%) & - & Rp. 44.836 .039 \\
Total & Rp. $\mathbf{4 2 8 . 8 6 2 . 5 0 0}$ & Rp. 493.196.487 \\
Unit yang dihasilakan & 4095 & 4095 \\
Harga jual per Kg & $\mathbf{R p . 1 1 0 . 0 0 0}$ & Rp. 120.438 \\
\hline
\end{tabular}

Sumber: Data Hasil Olahan

\section{KESIMPULAN DAN SARAN}

\subsection{Kesimpulan}

Berdasarkan hasil penelitian tentang penerapan metode full costing dalam penentuan

harga jual produk perusahaan, maka penulis dapat mengambil beberapa kesimpulan yaitu:

1. Perusahaan memang sudah menghitung biaya produksi produk tuna loin produk Frozen Yellowfin Tuna Loin Grade AAA (3 lbs up) dan Frozen Yellowfin Tuna Loin Grade A (1-3 $l b s)$. PT. Blue Ocean Grace International dalam menghitung biaya produksi belum sesuai dengan teori untuk penentuan harga jual poduk. Biaya yang belum dibebankan diantaranya biaya overhead pabrik yang meliputi penyusutan mesin dan peralatan, biaya bahan baku penolong, dan biaya asuransi.

2. Menurut perhitungan perusahaan, perusahaan memiliki biaya bahan baku sebesar Rp.819.000.000, biaya tenaga kerja sebesar Rp. 83.790.000, dan biaya overhead pabrik sebesar Rp.110.008.833, dibagi dengan hasil produk jadi yaitu 9555 unit sehingga akan mendapatkan biaya produksi sebesar Rp.105.996/kg untuk produk Frozen Yellowfin Tuna Loin Grade AAA (3 lbs up). Penentuan harga jual produk Frozen Yellowfin Tuna Loin Grade AAA (3 lbs up) perusahaan mempertimbangkan kualitas mutu produk yang sangat baik dan produk biasanya diekspor ke luar negeri, sehingga perusahaaan menetapkan harga jual Rp. 120.000. Biaya bahan baku sejumlah Rp.351.000.000, biaya tenaga kerja sebesar Rp. 35.910.000, dan biaya overhead pabrik sebesar Rp.41.952.000 dibagi dengan hasil produk jadi yaitu 4095 unit sehingga akan mendapatkan biaya produksi sebesar Rp. 104.728/kg. Penentuan harga jual produk Frozen Yellowfin Tuna Loin Grade A (1-3 lbs) perusahaan mempertimbangkan kualitas mutu produk yang baik dan produk dijual hingga ke luar kota, sehingga perusahaaan menetapkan harga jual Rp. 110.000.

3. Perusahaan belum menerapkan sistem full costing karena perusahaan telah menetapkan harga berfokus pada kualitas produk yang jadi, dan harga kerjasama dengan konsumen. 
4. Dengan penerapan metode full costing, maka harga jual produk akan naik sebesar Rp. 124.296 untuk produk Frozen Yellowfin Tuna Loin Grade AAA (3 lbs up) dan Rp. 120.438 untuk produk Frozen Yellowfin Tuna Loin Grade A (1-3lbs).

\subsection{Saran}

Berdasarkan hasil analisis dan kesimpulan, maka penulis dapat memberikan saran sebagai berikut:

1. Baiknya perusahaan untuk menerapkan sistem full costing agar dapat meningkatkan harga jual dari produk tuna loin dengan perusahaan menghitung biaya produksinya secara tepat.

2. Perusahaan menerapkan metode full costing untuk kedua produk yaitu Frozen Yellowfin Tuna Loin Grade AAA (3 lbs up) dan Frozen Yellowfin Tuna Loin Grade A (1-3 lbs) karena metode full costing membebankan biaya secara variable dan tetap, sehingga dapat menghitung seluruh biaya yang keluar dari proses produksi.

3. Dalam menetapkan harga jual, perusahaan baiknya juga memperhatikan seluruh-seluruh biaya yang keluar dari proses produksi kedua produk Frozen Yellowfin Tuna Loin Grade AAA (3 lbs up) dan Frozen Yellowfin Tuna Loin Grade A (1-3 lbs). Tidak hanya dari kualitas hasil produksi dan kualitas mutu produk.

\section{DAFTAR PUSTAKA}

Abdullah, Akmal. 2014. Analisis Perhitungan Biaya Produksi Berdasarkan Metode Full Costing Dalam Menentukan Harga Jual Produk Lemari. Jurnal Universitas Halu Oleo.

Ahyari, Agus. 2011. Managemen Produksi: Perencanaan Sistem Produksi, Edisi ke 5, Cetakan -4. Jakarta.

Dunia, A., Firdaus, A. dan Abdullah, W. 2013. Akuntansi Biaya. Salemba Empat. Jakarta.

Fahmi, Irham. 2014. Manajemen Produksi dan Operasi. Alfabeta. Bandung.

Gersil, A. dan Kaydal, C. 2016. A Comparative Analysis Of Normal Costing Method With Full Costing And Varable Costing In Internal Reporting. Journal Internasional Celal Bayar University.

Hidayat, L. dan Salim, S. 2013. Analisis Biaya Produksi Dalam Meningkatkan Profitabilitas Perusahaan. Jurnal Sekolah Tinggi Ilmu Ekonomi Kesatuan Bogor.

Leven, Linnea, Cullbrand, Magnus. 2012. Spare Parts Pricing Setting The Right Prices For Sustainable Profit at Atlet. Journal of International Economics.

Mulyadi. 2015. Akuntansi Biaya. Edisi kelima. Cetakan ketigabelas. UPP STIM YKPN, Yogyakarta.

Qiao Zhilin, He Yi Chen Lin. 2014. Product Based on Activity Based Costing. Journal International Accounting.

Runtu, Jessica. 2016. Peranan Job Order Costing Method Dalam Menentukan Harga Pokok Produksi (Studi Kasus Pada Cv. Trinity Manado). Jurnal EMBA Vol.2 No.2 Juni 2014.

Samryn, L. M. 2013. Akuntansi Manajemen. Edisi Pertama. Kencana. Jakarta.

Simamora, Henry. 2012. Akuntansi Manajemen. Edisi III. Star Gate Publisher. Duri. Riau.

Sujarweni, V. 2015. Akuntansi Manajemen Teori dan Aplikasi. Penerbit Pustaka Baru Press. Yogyakarta.

Surjadi, Lukman. 2013. Akuntansi Biaya : Dasar-dasar perhitungan harga pokok. Cetakan Pertama. PT. Indeks. Jakarta.

Thontowi, Yeni, dan Rizal, S. 2012. Analisis Efektivitas Pengendalian Biaya Produksi Pada PT. Daur Ulang Sejahtera (DSA) Di Bandar Lampung. Jurnal Universitas Bandar Lampung. 
Wedin, Axel. 2012. Advanced Pricing Arrangements-Development of The Swedish Legislation. Journal International Accounting.

Widilestariningtyas, O., Anggadini, D. dan Firdaus, D. W. 2013. Akuntansi Biaya. Edisi Pertama. Penerbit Graha Ilmu. Yogyakarta.

Witjaksono, Armanto. 2013. Akuntansi Biaya. Graha Ilmu. Yogyakarta.

Woran, Ilat, dan Mawikere. 2014. Penentuan Harga Jual dengan Menggunakan Metode Cost Plus Pricing Pada UD. VANELA. Jurnal EMBA Vol.2 Juni 2014. Manado.

Worotijan, Calvin. 2016. Analisis Perhitungan Biaya Produksi Pada PT. Manado Nusantara Informasi (Koran Sindo). Jurnal EMBA Vol.4 No.1 Maret 2016.

Wuryansari. 2016. Analisis Perhitungan Harga Pokok Produksi Dengan Menggunakan Metode Full Costing Sebagai Dasar Penentuan Harga Jual (Studi Kasus di Peternakan Seraphine Yogyakarta). Skripsi. Universitas Sanatha Darma.. Yogyakarta.

Zaimal, Aripin. 2014. Analis Harga Pokok Produksi Tahu-Tempe pada Home Industry Lela Jaya. Manna. Jurnal Universitas Bengkulu. 